\title{
Spontaneous reversion of paroxysmal atrial fibrillation detected by smart watch
}

\author{
Liam Toner 두 , ${ }^{1,2}$ Ahmed M Al-Kaisey (1) , Anoop Koshy, ${ }^{1}$ Han Sung Lim ${ }^{1,2}$
}

${ }^{1}$ Department of Cardiology, Austin Hospital, Melbourne, Victoria, Australia ${ }^{2}$ Department of Cardiology, The Northern Hospital, Melbourne, Victoria, Australia

\section{Correspondence to} Dr Liam Toner; liam.toner@nh.org.au

Accepted 13 January 2020

\section{DESCRIPTION}

Atrial fibrillation (AF) is the most common cardiac arrhythmia and is associated with heart failure, cardioembolic stroke and increased overall mortality. ${ }^{1}$ Periodic 24 hours Holter monitoring is traditionally used to assess adequacy of rate control and direct titration of medical therapy. With the growth of smart watches that estimate heart rate (HR), there is increasing interest regarding the utility of these devices for chronotropic assessment and arrhythmia detection. ${ }^{2}$ Smart watches continuously estimate heart rate using optical detection of photoplethysmographic signals from infrared light emitting diodes where each pulsatile signal corresponds to a heartbeat. ${ }^{3}$

We present the case of a patient with known AF whose spontaneous reversion to sinus rhythm (SR) was detected as a sudden and persistent decrease in HR as measured by their smart watch and confirmed by a concurrently fitted Holter monitor.

An 80-year-old woman with a known history of paroxysmal atrial fibrillation underwent routine ambulatory Holter monitoring to assess the adequacy of ventricular rate control. On returning the Holter monitor the next day, she reported the sensation of her heart 'doing a flip' at 19:29 as she noted her heart rate suddenly drop from $99 \mathrm{bpm}$ to $65 \mathrm{bpm}$ as measured by her Apple Watch Series 3 (Cupertino, USA). Review of the Holter monitor revealed she had reverted from $A F$ to $S R$ at that time, figure 1 . The heart rate recordings from the Apple Watch were extracted and synchronised to the Apple Health App (Cupertino, USA) and then exported to Microsoft Excel. A total of 199 heart rate readings were recorded from the Apple Watch and matched to 199 readings of the same time intervals on Holter monitoring over a 22-hour period as shown in figure 2 (median interval $6 \mathrm{~min}$

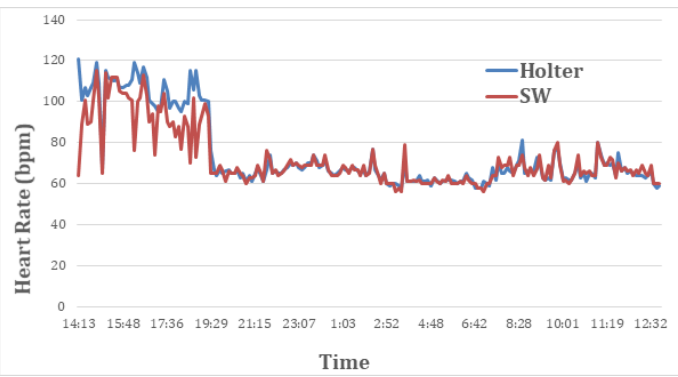

Figure 1 Heart rate versus time as recorded by the smart Watch (red) and Holter monitor (blue). reversion from atrial fibrillation to sinus rhythm occurred at 19:29.

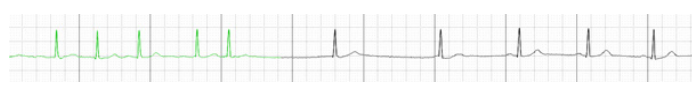

Figure 2 Rhythm strip as recorded by the Holter monitor at 19:29 demonstrating atrial fibrillation (green) followed by two junctional beats then reversion to sinus rhythm.

and IQR of $5.75 \mathrm{~min}$ ). Moreover, the average HR as measured by smart watch in AF prior to reversion was 94 bpm compared with 66 bpm after reversion to SR.

Our key finding is that a sudden and persistent alteration in HR on a wearable device may be suggestive of a subclinical arrhythmia. This case highlights the advantage of incorporating continuous capture photoplethysmography with contemporary single-lead ECG technology to facilitate chronotropic and rhythm assessment of patients with atrial fibrillation.

\section{Learning points}

- Sudden and persistent changes in heart rate as detected by smart watches should alert clinicians to the possibility of cardiac rhythm changes.

- The patient outcomes and management of arrhythmias detected by smart watch heart rate monitoring are the subject of ongoing research.

Contributors All authors have contributed to the manuscript and have approved a final version of the manuscript. LT—data analysis, manuscript preparation. AMAK — data analysis, manuscript preparation and editing. AK-data analysis, manuscript preparation and editing. HSL-planning, conception and manuscript editing.

Funding The authors have not declared a specific grant for this research from any funding agency in the public, commercial or not-for-profit sectors.

Competing interests None declared.

Patient consent for publication Obtained.

Provenance and peer review Not commissioned; externally peer reviewed.

\section{ORCID iDs}

Liam Toner http://orcid.org/0000-0002-7288-3362

Ahmed M Al-Kaisey http://orcid.org/0000-0001-5174-1034

\section{REFERENCES}

1 Benjamin EJ, Wolf PA, D'Agostino RB, et al. Impact of atrial fibrillation on the risk of death: the Framingham heart study. Circulation 1998;98:946-52.

2 Koshy AN, Sajeev JK, Nerlekar N, et al. Smart watches for heart rate assessment in atrial arrhythmias. Int J Cardiol 2018;266:124-7.

3 Sajeev JK, Koshy AN, Teh AW. Wearable devices for cardiac arrhythmia detection: a new contender? Intern Med J 2019:49:570-3. 
Copyright 2020 BMJ Publishing Group. All rights reserved. For permission to reuse any of this content visit https://www.bmj.com/company/products-services/rights-and-licensing/permissions/

BMJ Case Report Fellows may re-use this article for personal use and teaching without any further permission.

Become a Fellow of BMJ Case Reports today and you can:

- Submit as many cases as you like

Enjoy fast sympathetic peer review and rapid publication of accepted articles

Access all the published articles

Re-use any of the published material for personal use and teaching without further permission

Customer Service

If you have any further queries about your subscription, please contact our customer services team on +44 (0) 2071111105 or via email at support@bmj.com.

Visit casereports.bmj.com for more articles like this and to become a Fellow 